\title{
A Case of Allergic Dermatitis that Healed Completely After Ten Intradermal Injections with a Non-Specific Antigen Preparation
}

\author{
Kimihiko Okazaki* \\ Okazaki Medical Clinic, Ukyoku Kyoto Japan
}

*Corresponding Author: Kimihiko Okazaki, Okazaki Medical Clinic, Ukyoku Kyoto Japan, Email: ma13081x@mal.seikyou.ne.jp

\section{INTRODUCTION}

According to the traditional concept of the contemporary Immunology, neither autoimmune diseases nor allergic diseases can be cured completely. Nevertheless, a fortunate coincidence led the author to discover a novel concept that eliminations of the causes of these diseases are possible. In other words, combinations of pathogenic antibodies with responsible cells, namely, cytolytic $\mathrm{T}$ lymphocytes in cases of autoimmune diseases and mast cells in cases of allergic diseases, can be decomposed by replacing the pathogenic antibodies with non-specific antibodies. In more detail, intradermal injections with a non-specific antigen preparation induce productions of nonspecific antibodies in the body of the patient. Repetitions of the injections bring about an accumulation of them. Accumulated non-specific antibodies will occupy most of the receptors on the surface of responsible cells. When the accumulation reaches the sufficient level, virtually no pathogenic antibodies would remain on the receptors. That is, no causes of the diseases remain.

It is well established that the etiology of allergic diseases is that combinations of mast cells and allergen-specific antibodies cause allergic symptoms when the patients meet allergens. Similarly, the etiology of auto-immune diseases is that combinations of cytolytic $\mathrm{T}$ lymphocytes and organ-specific antibodies cause injury of the organ. A most plain idea would be that break down of the above-mentioned combinations must bring about disappearance of causes of the diseases. To work out the above mentioned concept, it is necessary to have the patients make non-specific antibodies for themselves. In order for the patients to do so, they need to receive intradermal injections with non-specific antigen preparations. Consequently, non-specific antibodies accumulate in the patients' bodies, which may replace specific antibodies from respective cells bringing about elimination of causes of the diseases. Needless to mention, where there is no cause, there is no disease. Details are demonstrated elsewhere (1). The conceptual basis of antibodies' mutual exchange is existence of equilibrium state among antibody molecules in the vicinity of receptors, which was first proposed by Porter (2). One of the contemporary trends concerning treatments of allergic diseases is an intravenous infusion of solution of non-specific antibody preparation. However, a large number of these infusions are dangerous because anti-antibody antibody might be produced in the recipient's body, which may cause an anaphylactic reaction.

\section{CASE 1}

A 72-year-old woman(E.H.) visited the author's clinic on June 3, 2016. She said that she had had itchy maculae of both-sides hands, fingers, feet, abdomen, back, and hips since the end of March, 2015. She visited a Dermatologist and was diagnosed as allergic dermatitis. She kept taking oral anti-histaminic agent and using ointment until she started receiving the author's treatment.

She started receiving an intradermal injection with $0.1 \mathrm{ml}$ of 10 to the 8 -fold with saline diluted Neurotropin; a product of Nippon Zohki Pharmaceutical Company(Osaka), consisting of an extract of rabbit skin inflamed by inoculation of Vaccinia virus, on June 3, 2016 at her upper arm changing sides alternatively at $2 \sim 3$ day intervals until June 24, 2016. As of March 13, 2018

she was free of any skin-trouble. The total number of injections was just ten. 
A Case of Complication of Bronchial Asthma and Rheumatoid Arthritis both of which Healed Completely after Repeated Intradermal Injections with a Non-Specific Antigen Preparation

\section{REFERENCES}

[1] Okazaki, K. (2009): Therapeutic Significance of Non-Specific Antigens as Anti-Allergic and Anti Autoimmune Agents, Pharmacometrics, 76: 105-107.
[2] Porter, R.R. (1959): The hydrolysis of rabbit gamma-globulin and antibodies by crystalline papain, Biochem. J., 73: 119.

Citation: Kimihiko Okazaki. A Case of Allergic Dermatitis that Healed Completely After Ten Intradermal Injections with a Non-Specific Antigen Preparation. ARC Journal of Clinical Case Reports. 2018; 4(1): 11-12. doi:dx.doi.org/ 10.20431/2455-9806.0401004.

Copyright: (C) 2018 Authors. This is an open-access article distributed under the terms of the Creative Commons Attribution License, which permits unrestricted use, distribution, and reproduction in any medium, provided the original author and source are credited. 